\title{
The Humanistic Approach of Adult and Tertiary Education
}

\author{
A. Mészáros' ${ }^{1}$ E. Baróti² \\ ${ }^{1}$ Széchenyi István University, Teacher Training Centre \\ Egyetem tér 1.9026 Győr, Hungary \\ Phone: +36 96503400 \\ e-mail: meszaros@sze.hu \\ ${ }^{2}$ Széchenyi István University, Department of Structural and Geotechnical \\ Engineering \\ Egyetem tér 1.9026 Győr, Hungary
}

\begin{abstract}
The environment of the 21st century adult and tertiary education has changed at several places. The obstacles of information flow have disappeared and the educational environment has been virtualized. At the same time, the learning habits of students have also changed radically. These changes should be followed by tertiary and adult education as well. By accepting these phenomena workers of tertiary and adult education have to face a lot of fresh challenges. It is very important for them to adjust to the trends mentioned above. Even those people who are not certified teachers need information, pedagogical and psychological knowledge to be able to find their way in the pedagogy of adult and tertiary education.
\end{abstract}

Keywords: tertiary education, the thinking barrier, the feeling barrier

\section{Introduction}

We need teachers who are able to accompany their students on their professional and fate learning way at the same time, thus new educational strategies are needed. The training of excellent teachers and trainers is one of the most urgent tasks of the future. Mass education has provided an opportunity for a lot of people to learn, and it can be regarded as success. On the other hand, it is very difficult to keep pace with the motivation and the differentiated knowledge of the entering students, and building relationships with them. There are not any pedagogical-methodological or teacherhuman answers to it and it cannot lead to real quality changes on the long term as the problems are only partly resolved.

Teaching in adult and tertiary education is a particular profession. It means much more than knowing a special field of science and conveying it. At the moment, the only quality indicators are the professional and scientific requirement expectations. Thus the field mentioned above should be improved by our own motivation due to the lack of 
expectations. We all meet the anxiety experienced because of the necessity, the invariability of ended things [6] To resolve this problem 'people training' should be integrated in the professional training of future universities. Education must not lose its humanistic aspects. [7] Furthermore, we need to make efforts to find the right profession-specific learning situations and methods on this teaching-studying way.

How can the attention receiving the intellectual impulse of the future generation be realized? How can we find the educational way to follow to be able to help our students to become professional and useful citizens? This study gives ideas to rely on when answering the above questions.

\section{The Adult and Tertiary Eduction as a Scene of 'People Training'}

The training should be life- and professional practice-oriented. The aim of the teachers is not to convey their own point of view to their students, but to help them develop their own ability to judge things. 'A Dean of a College of Technology stated that he often had to give a degree to engineers who completed their exams although he was convinced that they were not 'real' engineers. Being asked what he means by 'real engineers' he mentioned what social and cultural responsibilities those people should have who manage scientific research and production, but they were not prepared at all for taking such responsibilities. A lot of people become managers, but they have never learned to manage their fellows in an up-to-date way. So the 'people training' is also missing here' [2].

We mention only some of the phenomena:

- $\quad$ people are 'switched off' in education, so they just get passive knowledge

- the one-sided professional specialization is very narrowing, it has a lot of unfavourable social and personal side effects

- a kind of one-sided scientific authority predominates, the individual judgement becomes weaker

- The training has a conditional effect, a good example of it is the professional deformity which can be experienced later, and it can lead to being unsuccessful at the labour market

The adult and tertiary education has to meet two important requirements:

- Firstly, the profession and qualification have to be in focus in the adult and tertiary education. Every field of science needs different educational methods which have to be found by the determined teachers and representatives of the profession based on the impulses of the students. So we need to have a differentiated tertiary education pedagogy relying on the certain professional fields.

- Secondly, if a trained professional enters the labour market, he or she will take up a position in the society. Thus tertiary and adult education has not only to give the students professional qualification but high-quality human 
qualification as well because they have to be the bearer and transformer of present-day culture.

We can state that adult and tertiary education needs to find new ways that each professional field has to find for itself. They have to select the most suitable training methods relevant to the given professional field. The latest experiment in the technological field is the dual engineer training.

\section{The Human Integrating Basic Principles of the Adult and Tertiary Education}

We would like to describe principles that are essential at all kinds of trainings. There can be crises in all people's lives, and also moments when they do not know how to go on. People can get indecisive, their emotions can fluctuate, and they get puzzled. This is the moment of human development when people become internally active, they start searching for the purposes and aims of inner and outer happenings. From this point of view, the recent period is the 'trainer' of adults. Our safety and trust has disappeared, everything that used to be evident and valuable has collapsed. There are doubts and fears in people. We can only find safety in ourselves, if we make enough effort. According to Jung we cannot judge to what extent we talk about perception and recognition if we just talk about psychical thinking and we deny the non-psychical, supersensible condition [1].

The spirit of the age requires us to awaken our own will, therefore the adult and tertiary education need to define the achievement of the will-awakening of all the people as its goal. It can be regarded as the first basic principle.

The independent studying will is in connection with the nature of the human personality, which is in relation to the human will. The human will is most importantly vitality, which is connected to the human body and it accompanies all the physical activities. However, there is a so-called original 'intellectual heat', apart from the biological will, which comes to existence if the person becomes enthusiastic about something he or she regards as valuable or nice. If this enthusiasm is followed by an activity, the individual and the will are linked up. Acting in things which inspire us is the awakening of the will itself. Most of the studying process is created by this 'heat process'. The three basic (usually unconscious) driving forces in studying represent the biologically bounded will being present in all the people: the tendency to recognize, develop and improve.

- The desire to recognize helps people adapt to the basics of the outside world, it maintains a constant process which tries to find out the human mystery. Its goal is to find the bridge that is necessary to be able to understand the world and ourselves.

- The desire of the human soul to improve is essential in the learning process. Through our walk of life in certain life cycles it is transformed again and again, it changes and we learn in different ways in our early or later cycles of life. 
- The most unconscious willpower is the tendency to improve and also the feeling that we could have done everything in a better way. At the same time we realize that we have not achieved the state of perfection yet.

As a trainer we can have an essential question how to awaken these internal motivations in our students, because it requires a suitable methodology. A methodology which helps the students to become independent, supports the creation of his/her inner autonomy, the will to learn and judge independently, which is nourished by the three basic principles mentioned above. The training institutions need to be examined from the point of view that their courses improve the will and the personal judgement. It should be regarded as one of the main principles of high-quality education.

The second basic principle is based on the three resistance and working on them in the learning process. We acknowledge all the three barriers as equal. These resistances can be seen as three obstacles in our thinking-feeling and will world. We realize it as an obstacle which cannot be overcome and it generates fears and revulsions in ourselves. We reckon that we will not be able to cope with our tasks. So we need courage to be able to analyze these feelings and integrate them into our conscience not only by using the analytical intellectualization but the imaginative way of thinking which helps us to understand things more deeply.

Our system of feelings move in two directions: towards our thoughts and will. That is why it is important to learn how to examine our feelings with our thoughts and to strengthen our positive feelings with the help of our will. The tertiary and adult educations have to recognize that the learning process is based on the work on these three contrariness and to find the right balance between them. The real change comes with the learning of essential things.

All the trainings that do not encourage the work on the 'human central' and emphasize one of the three obstacles may displace the human from his/her balance causing a lot of dangers. 'The intellectual overemphasis without the connection of the balancing practical activities, the drilling of different skills without the real recognition. So the intellectualization and the drilling without the evaluating and connecting element of the feelings can lead to deformation, concretion and one-sidedness, moreover, to the damage of the whole learning process.' [2].

Thus it is a most important principle in the education and the learning process based on the three resistances: the barrier of thinking, feeling and willpower and working on them. This balance is very difficult to be made because people tend to overemphasize one of the above mentioned barriers. On the other hand, in the tertiary education and adult education a lot of effort is made to achieve this 'barrier balance', and the learning process based on the resistances, will yield and create the strongest power of mind and also build up moral power in the human soul. Let us have a look at these three resistances as the obstacles to be present and overcome in the learning process. 


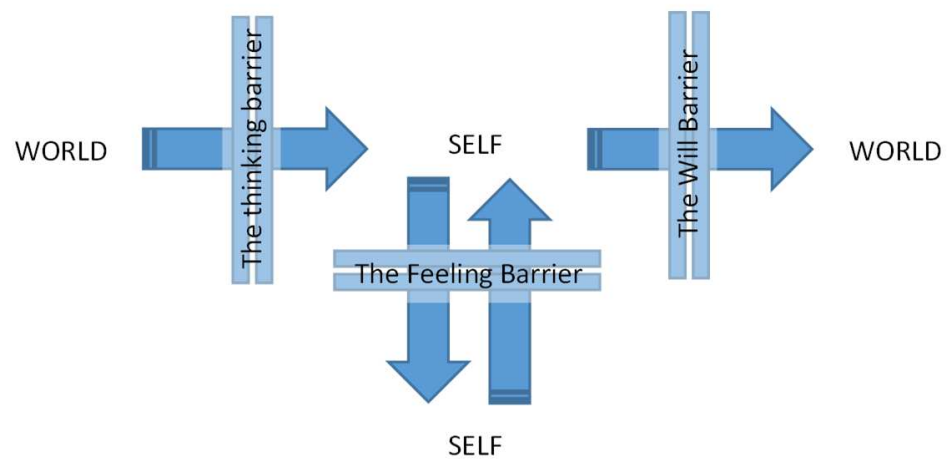

Figure 1: The barriers appearing and to be overcome in the learning process [2]

\subsection{The thinking barrier}

The ancient Greek philosophers started to examine the epiphany of human existence systematically. They found out that the thinking process has its rules and barriers as well [3]. Thus the people determined to recognize things meet new mysteries that help them to recognize the barriers of thinking. We have to recognize that the thorough observation of concrete things or the grabbing of abstract intuitive reality is more important for us. This is a threshold between the world and the human self. Our models of thinking only help to get to know a certain part of the world, the other reality is hidden and to be recognized.

The tasks of working on the thinking barrier can be the following:

- questioning and researching behaviour instead of passive knowledge acquisition

- we have to take care of the objective observation skill through our twelve sense organs as well as the skills of thinking because these two together can lead us to the truth

- we have to discover the difference between convergent and divergent way of thinking in our thinking skills and we have to be able to use them side by side. We have to develop our convergent way of thinking by a lot of effort and concentration, carrying out a thinking process step by step according to cause and effect and logical range coming to an exact consequence. To develop divergent way of thinking we only need to realize if we have an intuitive perceptivity and we need to open ourselves to this quick perceptive and spontaneous, creative way of thinking and recognition.

- we need to learn to differentiate between the things we know and the things we understand. The real understanding and learning is only possible if we work on all the three barriers.

- we have to recognize the one-sidedness in our thinking and if we have analytical, synthetic, imaginal or descriptive way of thinking. 
Each person has a different way of thinking, so the teacher can never meet everybody's requirements. He/she needs to act as an advisor to be able to diagnose and overcome the obstacles. The student learns to face the outside world and understand its principles so that he/she can avoid making a mistake by adopting things without deeper understanding. A basic moral force being created during this process is the feeling of devotion, respect to the things of the world and to other people. At the same time it enables people to be devoted and recognize the values.

\subsection{The Feeling Barrier}

Here we meet a resistance that is shown in our feelings. This is not the relationship between the individual and the outside world but the one between the individual and her/himself and it is associated with the teacher and the participating students. Working on the feeling barrier gives people self-understanding, liberation and the inner maturity of the personality. They can experience that their feelings are very important elements of the learning and cognitive process. However, working on this barrier seems to be the most difficult and the least accepted among the trainers and the people participating in the learning process.

We can see a lot of resistance in the case of the trainers and they object to the fact that working on the inside feeling barrier is part of the learning process. Here the trainer stands in front of his/her own threshold. He/she has to decide if he/she is involved and lives through his/her own feelings and integrates it into the learning process encouraging his/her own students to do the same or stay in his/her authoritative, deformed, conditioning position without any empathy. However, with the exclusion of the personal feelings the learning process cannot contribute to the personal development. Working on the feeling barrier cannot only lead us to the recognition of ourselves but to the transcendent as well. The word 'knowing' is anomalous in this context because it suggests that the world can be recognized without feelings [5]. Therefore it is necessary for the trainer to have a friendly, emphatic attitude and recognize the values without criticism to be able to overcome this obstacle.

Only the working on this barrier can lead the learning process to self-recognition. The trainer can support the learners with helping interviews on this way. However, we confess that he/she should have bravery, resolution and self-recognition to be able to work on this barrier in the learning process and he/she is not trained for it for the time being. In many cases the students refuse the learning process because of the lack of working on this central field.

Working on this barrier can build up the moral force based on the loving ability empathy with the other self.

\subsection{The Will Barrier}

The basic feature of the willing resistance is the anxiety which exists inside us in a hidden way. The will barrier means a sort of action limit. This is the relationship of the self and the world. The inside desire to create and make things better is a willing impulse which make us take action. We would like to impress the outside world and make it change by assessing the possible outcome or instinctively, driven by an inside 
unconscious impulsion. A lot of people learn from their actions, 'get to know something by grabbing the world in an active way'. They are the extrovert type of people. Those, who are keen on experimenting and lead their way to discovery. In the era of today's modern information technology these actions are given in advance, do not occur with the conscious leading of the self and do not occur by grabbing the personal individual will.

There are people who refrain from immediate actions, are introvert and tend to think things over before acting. In many cases there is a will paralysis that hinders actions and prevents us from approaching the thinking, feeling and will barriers actively. In training institutions we often experience that the learning will of our students is too weak, they tend to give up too soon if they have to face any difficulties, they do not have enough stamina etc. There is anxiety in the background which can be regarded as a barrier. In a learning process the most important problem manifests itself in the willing region. The fear of life, changes and future hinders the activity and it can lead to a sort of paralysation or mechanical actions which do not involve the cognitive and developmental objectives necessary for the personal and professional improvement, and lead to the correct adaptation of the learning process. Therefore the most important task of the trainer is to awaken the individual learning will by experiencing the effort of working on the three barriers in him/herself. Thus the training and teaching profession requires a continuous inside observation and the maintenance of flexibility, spontaneity, self-recognition, and the ability to learn and develop. It needs a kind of participation, the involvement of the individual personality. Meeting its requirements and the participation is a profession where similar abilities and maturity are needed. The understanding and the use of the Myer-Briggs theory can help to increase the standard of the teaching profession and the cognitive-information theory interpretation as well [9].

Some inspiring methods to awaken the own personal will of our students:

- the formation of a concrete creation containing artistic and new elements as well. It addresses the creative part of people and helps the connection with the substance, the physical reality. It also starts a spontaneous, creative process, which can be regarded as a pattern for a further learning process needing a deeper participation.

- a designing task, project work, which has an opened outcome

- teamwork, where cooperation is necessary which requires strong commitment and in this way it stimulates the will mainly in the case of groups

- developing evaluation and feedback methods

The work on this barrier builds up the third shell of moral force, the force of wisdom in the self which improves the ability to take responsibilities.

It is obvious that this learning process can address the whole personality and provide help and support in the process of preparing him/her for the future. 
The third basic principle is based on the correct interpretation of the trainer-educator and student-participant relationship. We cannot ignore the relationship in the past and the custom of today which is inherited by the oncoming generation. In the past, the teachers and the professors were regarded as wise people, they were the masters of the given scientific fields, specified the learning way for their students who respected, awed them and were dedicated to the curriculum as well. These two basic moods are still present at the training institutions, especially the traditional universities having long histories. So coping with these tasks needs changes and effort from the side of the teachers and the students. It is about the meeting of two people: the university teacher and the university student according to the tertiary education denomination. In adult education it has a less hierarchical denomination proportional to the activity in the teaching-learning process.

This relationship takes place at three levels. At the first level the trainer the student $i$ preceded by the teacher from the point of view of curriculum and professional knowledge, otherwise he/she could not be a trainer. He/she makes his/her knowledge available for the students. The trainer stands above the student regarding his/her knowledge, he/she is superior. The second level is about human relationships where the two people need to be equal. At this level the inevitable meeting of two people and the emitting take place. The only choice to make the relationship work is the coequality; both people appear with their strengths and weaknesses in the relationship. The subordination and super ordination level off here. At the third level the participant is in the focus, the trainer supports and serves his/her learning process. In the case of an optimal learning process their task is to change these three behavioural types and to find a balance and the appropriate attitude at the given levels. This basic principle also contributes to the creation of the suitable learning process.

Apart from the three levels the teachers need to make a creative knowledge transferring environment, too. This is important from three aspects; on the one hand we have to access the field we want to work in. On the other hand, the interactions are very frequent in a creative environment, so we need to realize a bigger emotional and thinking effervescence in the education. Thirdly, the educational institutions realizing new ideas stimulate the general condition of the teachers and the students as well. On the contrary, a barren area is left by the people who long for a better one [4].

\section{Summary and Future Orientation}

We have searched for answers, how we can think differently in tertiary and adult education, how we can put the focus from the knowledge transfer to the people whom we want to train to be a professional. When we talk about changes, it is about processes, where there are some new things shown, things that we have not seen before [10]. How can we move away from the usual thinking and methodological ways which have become void and how can we make them up-to-date and renew our own teaching habits? How are the teachers motivated? What would be the right direction to the cultural changes of the tertiary and adult educational structure in the future?

Our students long for the fire found and looked after in our soul. They are not curious about the content, because they learn quickly if they find a goal. This is an inner process, which we can only achieve by struggling; it is like a birth, realizing our own 
personality and goals. This is the field where they need the biggest help. Without our understanding human support they are like a sleeping lost generation. So we must not forget that they rely on us. 'We tread on their dreams.' [8].

Only by doing it can comes a real quality into existence in education. At a prosperous university it is very important to create teacher workshops where people can talk about and process the questions of education. Where those people who want to improve and are sceptical to themselves can receive answers to their questions. Where in a teaching community there is a real quality measure of the responsible thinking and deeds for the future generation.

\section{References}

[1] Jung CG: Erinnerungen, Träume, Gedanken. Walter Verleg AG, Olten, 1971

[2] van Houten C: Erwachsenenbildung als Willenserweckung. Verlag Freies Geistesleben, 1999

[3] Csíkszentmihályi M: Creativity. Flow and the Psychology of Discovery and Invention. Harper Perennial, 2013

[4] Csíkszentmihályi M: The Evolving Self. A Psychology for the Third Harpers Collins Publishers, Inc, New York, 1993

[5] Kahneman D: Thinking, Fast and Slow. Penguin Books Ltd, London, 2011

[6] Riemann F: Grundformen der Angst Ernst Reinhardt, Basel/München, 1961

[7] Riemann F: Basic forms helfender partnership. Selected Essays (ed. and with an introd. of Mandel KH), Stuttgart, Klett-Cotta, 9th edition 2004

[8] Robinson K: Out of Our Minds: Learning to Be Creative. Capstone, Oxford, 2001

[9] MBTI types Books LLC, Reference Series, ISBN 115571119X, 2012

[10] Kast V: Sich wandeln und sich neu entdecken. Verlag Herder GmbH, Freiburg, 1996 